\title{
Measurement of thermal contact resistance of aluminum honeycombs
}

\author{
C.L. Yeh *, Y.F. Chen, C.Y. Wen, K.T. Li \\ Department of Mechanical Engineering, Da-Yeh University, 112 Shan-Jiau Road, Da-Tsuen, Chang-Hua 51505, Taiwan, ROC
}

Received 15 November 2001; accepted 9 September 2002

\begin{abstract}
An experimental investigation of thermal contact resistance of the aluminum honeycomb (made of Al3104-H19 and Al3003-H16) sandwiched by two aluminum blocks was conducted with the honeycomb specimens aligned in either axial or lateral orientations. Honeycombs adopted in this study include two different cell diameters $\left(d_{\mathrm{c}}\right), 6.3$ and $12.7 \mathrm{~mm}$, as well as two different axial heights $\left(H_{z}\right), 7.8$ and $14.8 \mathrm{~mm}$. For the axial tests, honeycomb sandwich specimens were jointed by four or eight pieces of bolts with an applied torque ranged from 1 to $6 \mathrm{~N} \mathrm{~m}$. The interfacial contact pressures of axial honeycombs under different bolt-joined conditions were measured by the pressure-measuring films. For the lateral tests, the honeycomb was simply inserted between two aluminum blocks without using bolts to fasten. Results show that due to the anisotropic nature in heat conduction and the close contact provided by bolted joints, the total thermal conductance of axial honeycomb is greater than that of honeycomb in the lateral orientation under the condition with the same specimen height. An increase of either the cell diameter or specimen height of honeycombs leads to a decrease of the axial total conductance. Moreover, the axial total conductance was substantially enhanced by a double of the number of bolts used in the assembly of honeycomb specimens. However, the influence of bolt torque on the axial total conductance was observed only for the honeycomb with $d_{\mathrm{c}}=6.3 \mathrm{~mm}$ and $H_{z}=7.8 \mathrm{~mm}$. Due to the difference in specimen joint conditions, the thermal contact resistance between the solid aluminum surface and a lateral honeycomb is larger than that with an axial honeycomb. Under the conditions tested in this study, the thermal contact resistance of honeycombs in the axial direction appears to be one order of magnitude smaller than the total resistance. Nevertheless, the contribution of the lateral contact resistance of honeycombs to the total resistance was quite significant, especially for the specimen with a small height. It was found that the contact pressure of bolt-joined honeycombs in the interface increases evidently with an increase of either the bolt torque or the number of bolts. The empirical correlations between contact pressure and applied torque were also obtained for different joint conditions.
\end{abstract}

(C) 2003 Elsevier Science Inc. All rights reserved.

Keywords: Aluminum honeycomb; Total thermal conductance; Thermal contact resistance; Effective thermal conductivity; Bolted joint; Contact pressure

\section{Introduction}

Honeycomb cellular materials have been known for the extensive use in many lightweight structures, such as satellites, aircraft, and high-speed trains. They are also efficient in the applications of impact energy absorption $[1,2]$ and sound insulation [3]. In addition, due to their exceptional characteristics in heat transfer, honeycombs have been employed in compact heat exchangers [4], solar collectors [5], thermal insulators [6], and catalytic burners [7]. All of these applications involve a junction

\footnotetext{
${ }^{*}$ Corresponding author. Tel.: +886-4-8511888x2118; fax: +886-48511215.

E-mail address: clyeh@mail.dyu.edu.tw (C.L. Yeh).
}

or an interface between the honeycomb and the joining material. Therefore, a thorough thermal analysis of any of these systems would require knowledge of both the thermal conductance of honeycombs and the interfacial contact resistance between the honeycomb and joining material.

A review of literature on the thermal conductance [812] has indicated a lack of experimental data of thermal contact resistance and total thermal conductance for honeycomb materials. Most of the previous studies on the thermal transport properties of honeycomb structures were analytically investigated. $\mathrm{Lu}$ [4] studied the transport of heat in aluminum honeycombs subjected to convective cooling using a corrugated wall model. Solutions were obtained for the thermal fields and overall 


\begin{tabular}{|c|c|c|c|}
\hline \multicolumn{4}{|c|}{ Nomenclature } \\
\hline$D$ & bolt-shaft diameter $(\mathrm{mm})$ & $k_{\mathrm{s}}$ & thermal conductivity of honeycomb raw ma- \\
\hline$l$ & length of one edge of a honeycomb hexagon & & terial $(\mathrm{W} / \mathrm{m} \mathrm{K})$ \\
\hline & $(\mathrm{mm})$ & $N$ & number of bolts \\
\hline$d_{\mathrm{c}}$ & cell diameter of a honeycomb hexagon $(\mathrm{mm})$ & $P_{\mathrm{c}}$ & contact pressure $(\mathrm{MPa})$ \\
\hline$H_{y}$ & $\begin{array}{l}\text { height of the lateral ( } y \text {-direction) honeycomb } \\
\text { specimen }(\mathrm{mm})\end{array}$ & $R_{\mathrm{c}}$ & $\begin{array}{l}\text { thermal contact resistance between alumi- } \\
\text { num block and honeycomb specimen }\left(\mathrm{m}^{2} \mathrm{~K} /\right.\end{array}$ \\
\hline$H_{z}$ & height of the axial (z-direction) honeycomb & & $\mathrm{kW})$ \\
\hline$h_{\mathrm{t}}$ & $\begin{array}{l}\text { specimen }(\mathrm{mm}) \\
\text { total thermal conductance of the honeycomb }\end{array}$ & $R_{\mathrm{t}}$ & $\begin{array}{l}\text { total thermal resistance of } \mathrm{Al} / \mathrm{HC} / \mathrm{Al}\left(\mathrm{m}^{2} \mathrm{~K} /\right. \\
\mathrm{kW})\end{array}$ \\
\hline & $\begin{array}{l}\text { specimen sandwiched by two aluminum } \\
\text { blocks }(\mathrm{Al} / \mathrm{HC} / \mathrm{Al})\left(\mathrm{W} / \mathrm{m}^{2} \mathrm{~K}\right)\end{array}$ & $t$ & wall thickness of the honeycomb cell (mm) \\
\hline$h_{\mathrm{t}, y}$ & lateral ( $y$-direction) total thermal conduc- & \multicolumn{2}{|c|}{ Greek symbols } \\
\hline & tance of $\mathrm{Al} / \mathrm{HC} / \mathrm{Al}\left(\mathrm{W} / \mathrm{m}^{2} \mathrm{~K}\right)$ & $\Delta T$ & temperature drop across the honeycomb \\
\hline$h_{\mathrm{t}, \mathrm{z}}$ & axial (z-direction) total thermal conductance & 0 & specimen $\left({ }^{\circ} \mathrm{C}, \mathrm{K}\right)$ \\
\hline & OI AI/HC/AI $\left(\mathrm{W} / \mathrm{m}^{-} \mathrm{K}\right)$ & $\rho$ & honeycomb density $\left(\mathrm{kg} / \mathrm{m}^{3}\right)$ \\
\hline & $\begin{array}{l}\text { comb specimen }(\mathrm{W} / \mathrm{m} \mathrm{K}) \\
\text { comberity of the honey- }\end{array}$ & $\begin{array}{l}\rho_{\mathrm{s}} \\
\tau\end{array}$ & $\begin{array}{l}\text { density of honeycomb material }\left(\mathrm{g} / \mathrm{cm}^{2}\right) \\
\text { applied torque }(\mathrm{N} \mathrm{m})\end{array}$ \\
\hline
\end{tabular}

heat transfer coefficients as functions of cell morphological parameters and heat transfer conditions. The apparent thermal conductivities of various cellular structures, including anisotropic honeycombs, Voronoi cells, and Johnson-Mehl models, were first calculated by $\mathrm{Lu}$ and Chen [13]. In the absence of forced convection, $\mathrm{Lu}$ and Chen [13] pointed out that the transport of heat across a honeycomb structure is dominated by conduction along the solid cell walls and thermal radiation among the cell walls. However, the contribution of thermal radiation is negligible even at relatively high temperatures $\left(\sim 600^{\circ} \mathrm{C}\right)$. Torquato et al. [14] applied the homogenization theory and discrete network analyses to study the effective thermal conductivity of honeycombs with a hexagonal, triangular, or square cell. Lakhal et al. [15] numerically studied the natural convection and conduction in inclined enclosures bounded by a honeycomb structure. The effect of natural convection within the honeycomb cells is negligible when the cell sizes are small $(<10 \mathrm{~mm})$ [16]. A model evaluating the effects of wall thickness, aspect ratio, and absorptivity of the wall on the radiative heat transfer across transparent honeycomb insulation materials was proposed by Kaushika and Arulanantham [6].

Because of the anisotropic nature of honeycomb structures, the underlying mechanisms associated with heat conduction across honeycombs are complicated. This paper presents the measured results of an experimental investigation of the effective thermal conductivity and thermal conductance of honeycomb specimens in atmosphere, as well as the thermal contact resistance of honeycombs sandwiched by two aluminum blocks. The specific objectives of this research were to study the effects of specimen specification and joint condition on the heat conduction properties of honeycombs. Experimental parameters associated with the honeycomb specimen included the cell size, height, and material. In order to explore the influence of interfacial contact, experiments were conducted with honeycomb specimens assembled in different joint patterns, including the variations in the number of bolts, bolt-shaft diameter, torque applied on bolts, and honeycomb orientation.

\section{Method of approach}

\subsection{Experimental setup}

The experimental setup, shown in Fig. 1, along with the details of the facility construction, operation, and accuracy, have been previously reported by Yeh et al. [17]. The test facility, consisting of a guard heater, a main heater, a test specimen, two copper disks, and a heat sink, was vertically aligned on the base plate. Both main and guard heaters were made of copper cylinders and were equipped with two $140 \mathrm{~W}$ cartridge heaters. During the experiment, the guard heater was maintained at the same temperature as the main heater to eliminate the axial heat losses. The heat sink located at the bottom of test samples was accomplished with a temperature-controlled copper cylinder, which was cooled by a steady flow of cold water circulated through a chiller system.

\subsection{Honeycomb specimens}

Five types of honeycomb specimens with hexagonal cells were used in this study. The specifications of hon- 


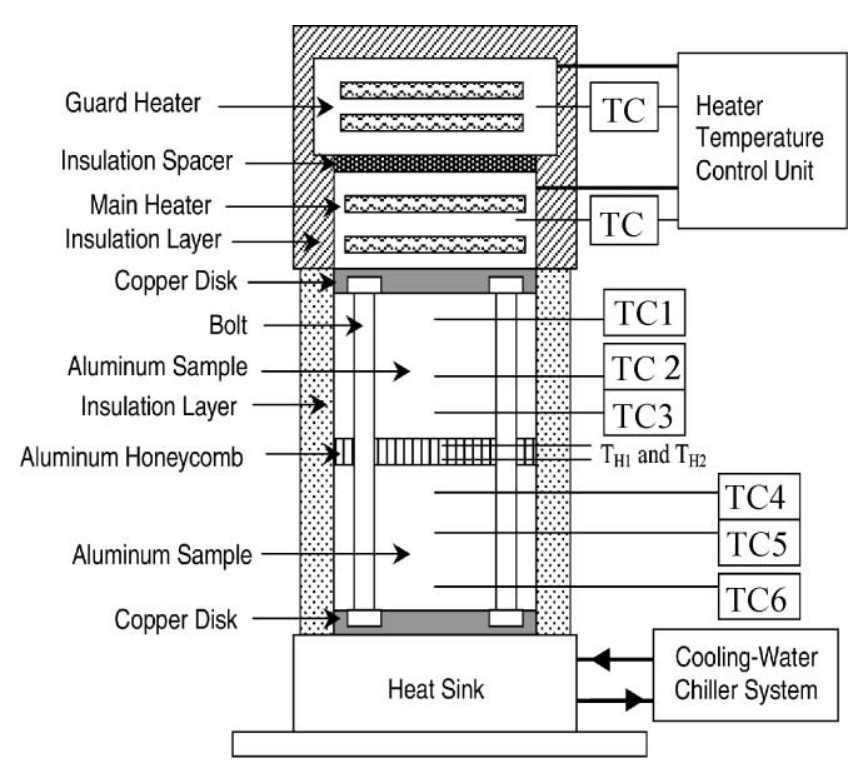

Fig. 1. Schematic diagram of experimental setup for the measurement of thermal contact conductance of aluminum honeycombs.

eycomb specimens are summarized in Table 1 . Honeycombs were made of two different types of aluminum alloys (A13104-H19 and A13003-H16). The thermal conductivity $\left(k_{\mathrm{s}}=170 \mathrm{~W} / \mathrm{m} \mathrm{K}\right)$ of Al3104-H19 aluminum alloy is higher than that $(157 \mathrm{~W} / \mathrm{m} \mathrm{K})$ of Al3003H16 alloy. For the Al3104-H19 honeycomb, specimen specifications consist of two different cell diameters $\left(d_{\mathrm{c}}=6.3\right.$ and $\left.12.7 \mathrm{~mm}\right)$, as well as two different axial heights $\left(H_{z}=7.8\right.$ and $\left.14.8 \mathrm{~mm}\right)$. The cell diameter, $d_{\mathrm{c}}$, is defined as the distance between two opposite walls of a honeycomb hexagon, as depicted in Fig. 2 showing one unit cell of a hexagonal honeycomb. The axial height of specimens represents the $z$-direction (axial) dimension of honeycombs. For the A13003-H16 honeycomb, the cell size and axial height are 12.7 and $7.8 \mathrm{~mm}$, respectively. As shown in Fig. 2, the honeycomb has non-uniform thickness of cell walls; that is, four walls of thickness $t$, and two walls of thickness $2 t$. This was caused by the manufacturing process of honeycombs through the corrugated metal sheets. The wall thickness, $t$, of honeycomb cells was $0.07 \mathrm{~mm}$ for all five specimens. As illustrated in Fig. 2, the $x$ and $y$ directions (also known as the lateral directions) are defined in the directions parallel and normal to corrugation, respectively. The $z$ di-

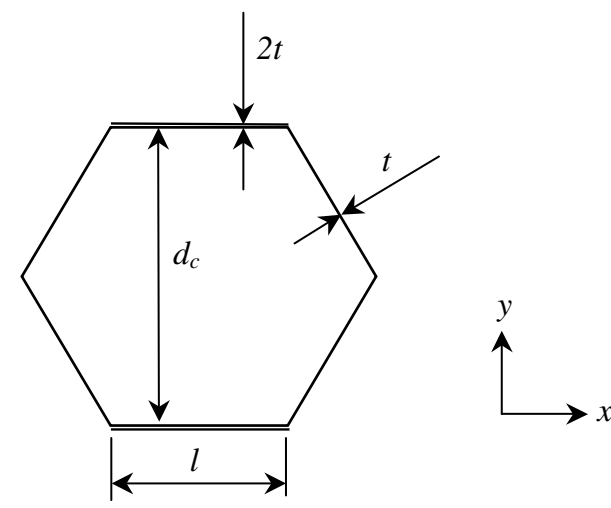

Fig. 2. Schematic diagram of one unit cell of a hexagonal honeycomb.

rection (i.e., the axial direction) is defined as the direction perpendicular to the $x-y$ plane. The density of honeycomb listed in Table 1 was calculated by the following equation [18]:

$\rho=\frac{8}{3 \sqrt{3}} \frac{t}{l} \rho_{\mathrm{s}}$

where $l$ is the length of one edge of a honeycomb hexagon and $\rho_{\mathrm{s}}$ is the density of honeycomb material, which was taken as $2.7 \mathrm{~g} / \mathrm{cm}^{3}$ for aluminum alloys.

\subsection{Axial heat transfer tests}

In the experiments, a honeycomb specimen was sandwiched by two aluminum (alloy 6061-T6) blocks with a square cross-section $(63.5 \times 63.5 \mathrm{~mm})$ and a height of $50 \mathrm{~mm}$, as shown in Fig. 1. These two aluminum blocks not only provided contact surfaces with the honeycomb, but also served as the heat flux meters. In order to measure the axial heat transport properties of honeycombs, the honeycomb was placed in a way of the hexagonal cells perpendicular to the contact surfaces of aluminum blocks. In other words, the heat flux was in a direction parallel to the $z$-coordinate of honeycombs. This type of sandwich structure with an axial honeycomb core is the most commonly used configuration for the honeycomb applications. Under this type of test conditions, the honeycomb specimen and two aluminum blocks were jointed by four or eight bolts. The bolts were made of low carbon steel (AISI 1010 steel). The thermal conductivity of AISI 1010 steel is about

Table 1

Specifications of honeycomb specimens

\begin{tabular}{lllcccc}
\hline $\begin{array}{l}\text { Specimen } \\
\text { no. }\end{array}$ & Aluminum alloy & $\begin{array}{l}\text { Alloy thermal con- } \\
\text { ductivity } k_{\mathrm{s}}(\mathrm{W} / \mathrm{m} \mathrm{K})\end{array}$ & $\begin{array}{l}\text { Height } H_{z} \\
(\mathrm{~mm})\end{array}$ & $\begin{array}{l}\text { Cell diameter } d_{\mathrm{c}} \\
(\mathrm{mm})\end{array}$ & $\begin{array}{l}\text { Wall length } l \\
(\mathrm{~mm})\end{array}$ & $\begin{array}{l}\text { Honeycomb density } \\
\rho\left(\mathrm{kg} / \mathrm{m}^{3}\right)\end{array}$ \\
\hline 1 & $3104-\mathrm{H} 19$ & 170 & 7.8 & 6.3 & 3.64 & 79.96 \\
2 & $3104-\mathrm{H} 19$ & 170 & 7.8 & 12.7 & 7.33 & 39.71 \\
3 & $3104-\mathrm{H} 19$ & 170 & 14.8 & 6.3 & 3.64 & 79.96 \\
4 & $3104-\mathrm{H} 19$ & 170 & 14.8 & 12.7 & 7.33 & 39.71 \\
5 & $3003-\mathrm{H} 16$ & 157 & 7.8 & 12.7 & 7.33 & 39.71 \\
\hline
\end{tabular}




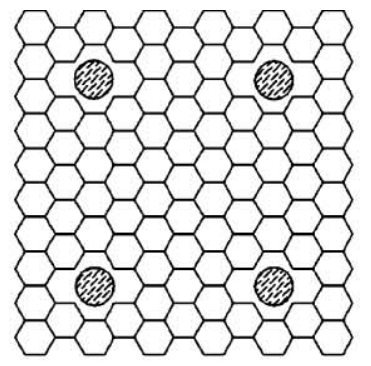

(a) $d_{c}=6.3 \mathrm{~mm}$ and $\mathrm{N}=4$

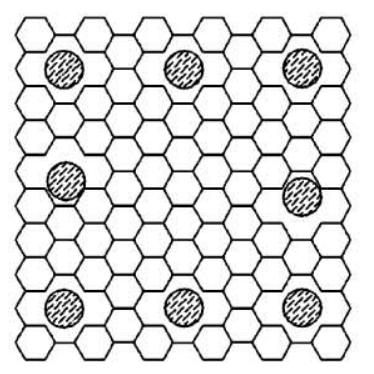

(b) $d_{c}=6.3 \mathrm{~mm}$ and $\mathrm{N}=8$

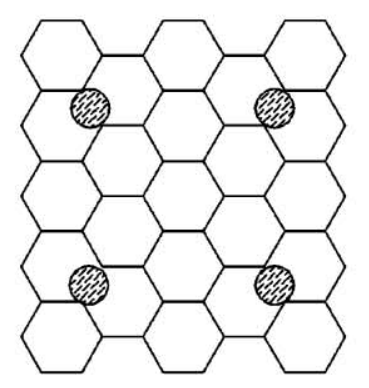

(c) $d_{c}=12.7 \mathrm{~mm}$ and $\mathrm{N}=4$

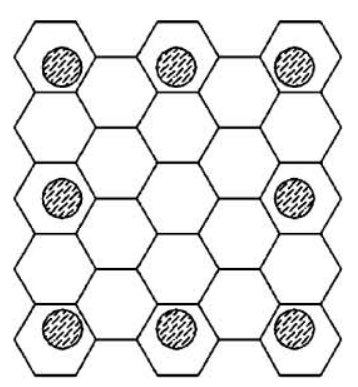

(d) $d_{c}=12.7 \mathrm{~mm}$ and $\mathrm{N}=8$

Fig. 3. Schematic diagrams of honeycomb specimens with the indication of bolt positions under different joint patterns.

$49.8 \mathrm{~W} / \mathrm{m} \mathrm{K}$, which is much lower than that $(170 \mathrm{~W} /$ $\mathrm{m} \mathrm{K}$ ) of aluminum alloy used in this study. Fig. 3(a)-(d) show the schematic diagrams of honeycomb specimens with the indication of bolt positions under different joint patterns. As shown in Fig. 3, certain cell walls of the honeycomb were purposely destroyed in order to facilitate the assembly of test specimens. The original hon- eycomb specimens with $d_{\mathrm{c}}=6.3$ and $12.7 \mathrm{~mm}$ consist of 105 and 23 hexagonal cells, respectively.

In this study, two different sizes of bolts with shaft diameters of 5 and $8 \mathrm{~mm}$ were used. Equal torque was applied on each bolt and the magnitude of torque $(\tau)$ was ranged from 1 to $6 \mathrm{Nm}$ for the honeycomb specimens with $d_{\mathrm{c}}=6.3 \mathrm{~mm}$. For the honeycombs with $d_{\mathrm{c}}=12.7 \mathrm{~mm}$, the torque on each bolt was only up to about $3.5 \mathrm{Nm}$, due to a lower crush strength for the specimens with a larger cell size. The torque was precisely measured by a torque wrench (Rahsol Dremometer Nr. 753) with the measurement range of 1-12 $\mathrm{Nm}$. After fastening the test assembly, two copper disks were placed on the top and bottom of the assembled specimen to accommodate the bolt heads and nuts. Another purpose of these two copper disks was to provide flat surfaces to make contact with the main heater and heat sink block.

In the assembled specimen, each aluminum block was instrumented with three K-type thermocouples with a known distance between each other, as shown in Fig. 1. The thermocouples were mounted in holes perpendicular to the axis of symmetry of the aluminum blocks. The accommodation holes were drilled to allow the thermocouple to be able to measure the center temperature at a cross-section of the aluminum block. In addition, in order to measure the effective thermal conductivity of honeycombs, two or three K-type cement-on thermocouples (Omega Co.), depending upon the height of specimens, were attached on the different positions of honeycomb cell walls for the surface temperature measurement. The $T_{\mathrm{H} 1}$ and $T_{\mathrm{H} 2}$, shown in Fig. 1, represent two cement-on thermocouples used to measure the wall temperatures of the honeycomb sample.

\subsection{Lateral heat transfer tests}

For the measurement of heat conduction properties in the lateral direction of honeycombs, the honeycomb specimen was sandwiched in such an orientation that the direction of heat flux was parallel to the $y$-direction of honeycomb cells. This arrangement of honeycomb orientation has been employed in the development of compact heat exchangers for the heat dissipation of high power electronics [4]. Because the pressure resistance (typically $0.2 \mathrm{MPa}$ ) of aluminum honeycombs was quite low in the lateral ( $x$ and $y$ ) directions [19], the lateral honeycomb specimen was simply inserted between two aluminum blocks without using bolts to fasten. Therefore, the loading pressure on the honeycomb specimen was accounted for both the atmospheric pressure and the weight of the upper aluminum block. The honeycomb specimens were carefully prepared to have flat contact surfaces with aluminum blocks, and the thickness of honeycombs between two aluminum blocks was specified in terms of the cell diameter. In this study, 
experiments were conducted with the honeycomb thickness (i.e, the lateral height, $H_{y}$ ) varied from one cell-diameter height to a lateral height equal to $2.5 d_{\mathrm{c}}$ for the honeycomb specimen with $d_{\mathrm{c}}=6.3 \mathrm{~mm}$.

\subsection{Data acquisition and analysis}

In the experiment, the heater temperatures were set at between 200 and $250{ }^{\circ} \mathrm{C}$, which corresponded to the heat flux ranged from 4 to $6.5 \mathrm{~kW} / \mathrm{m}^{2}$. Experimental data were taken when the temperature profile of test specimens achieved a steady-state condition, which was assumed to have been reached when none of the measured temperatures in the test specimens varied by more than $0.2{ }^{\circ} \mathrm{C}$ over a $1-\mathrm{h}$ period [17]. The temperature gradients in both heat flux meters (i.e., aluminum blocks) were obtained by applying a linear least-square fit to the measured centerline temperatures. To determine the temperature drop $(\Delta T)$ across the honeycomb specimen, the temperature profiles of both aluminum blocks were extrapolated to the upper and lower junction surfaces with the honeycomb specimen, respectively. Based upon the Fourier's law, temperature gradients and thermal conductivity of aluminum 6061-T6 were used to calculate the heat flux through each heat flux meter. An average of these two fluxes was used as an estimate of the heat flux across the honeycomb specimen. It was found in this study that the heat fluxes obtained from both aluminum blocks generally agreed to within $10 \%$. Under the assumption of uniform heat loss in the whole test assembly, the heat loss across the honeycomb sample is less than $1 \%$. This verifies that the test assembly was well insulated and the test duration of about $5 \sim 6 \mathrm{~h}$ was long enough to reach a steady-state one-dimensional heat transfer condition.

The total thermal conductance $\left(h_{\mathrm{t}}\right)$ of a honeycomb specimen sandwiched by aluminum blocks $(\mathrm{Al} / \mathrm{HC} / \mathrm{Al})$ is defined as the ratio of the mean heat flux $(q)$ across the honeycomb specimen to the temperature difference as follows:

$h_{\mathrm{t}}=\frac{q}{\Delta T} \quad\left(\mathrm{~kW} / \mathrm{m}^{2} \mathrm{~K}\right)$

The thermal resistance is referred to as the reciprocal of thermal conductance. Therefore, the total thermal resistance $\left(R_{\mathrm{t}}\right)$ of a honeycomb sandwich assembly can be written as

$R_{\mathrm{t}}=R_{\mathrm{Al} / \mathrm{HC}}+R_{\mathrm{HC}}+R_{\mathrm{HC} / \mathrm{Al}}=\frac{1}{h_{\mathrm{t}}}$

where $R_{\mathrm{Al} / \mathrm{HC}}$ is the interfacial thermal contact resistance between upper aluminum block and honeycomb specimen, while $R_{\mathrm{HC} / \mathrm{Al}}$ is the interfacial contact resistance between honeycomb specimen and lower aluminum specimen. The $R_{\mathrm{HC}}$ is the thermal resistance of honeycomb specimen and can be expressed as a function of the effective thermal conductivity and the height of honeycomb. That is,

$R_{\mathrm{HC}}=\frac{H}{k_{\mathrm{eff}}}$

where $H$ is the height of honeycomb, and $k_{\text {eff }}$ is the effective thermal conductivity of honeycomb.

Since the contact conditions of the upper and lower interfaces between the honeycomb specimen and two aluminum blocks were nearly the same, it was reasonable to assume that

$R_{\mathrm{Al} / \mathrm{HC}}=R_{\mathrm{HC} / \mathrm{Al}}=R_{\mathrm{c}}$

As a result, the thermal contact resistance $\left(R_{\mathrm{c}}\right)$ between the aluminum surface and the honeycomb specimen can be obtained as

$R_{\mathrm{c}}=\frac{1}{2}\left(\frac{1}{h_{\mathrm{t}}}-\frac{H}{k_{\mathrm{eff}}}\right)$

From Eq. (6), it is apparent that the total thermal conductance $\left(h_{\mathrm{t}}\right)$ of $\mathrm{Al} / \mathrm{HC} / \mathrm{Al}$ and the effective thermal conductivity of honeycomb $\left(k_{\text {eff }}\right)$ were measured in this study and the honeycomb height $(H)$ was known. Therefore, the thermal contact resistance $\left(R_{\mathrm{c}}\right)$ between the aluminum block and the honeycomb specimen can be deduced.

\subsection{Measurement of interfacial contact pressure}

The importance of interfacial pressure to the contact resistance has been well recognized. In this study, the contact pressure in the bolt-joined junction with the axial honeycomb was measured by the pressuremeasuring film (Fuji Prescale Film, Type: LW). With a Prescale film inserted between the honeycomb specimen and the aluminum block, once the torque was applied on bolts, the exerted pressure results in a color development on the film. The color density is a function of the magnitude of pressure. The calibration and image analysis procedures to convert the color density into the pressure were previously described [17]. In this study, the average axial pressure exerted on the honeycomb specimen was determined as a function of the bolt torque $(\tau)$, bolt size $(D)$, and the number of bolts $(N)$.

\section{Results and discussion}

\subsection{Temperature measurement and effective thermal conductivity}

Figs. 4 and 5 show the axial temperature distributions of upper and lower aluminum blocks and the temperature drops $(\Delta T)$ across the sandwiched honeycomb specimens in the axial and lateral orientations, respectively. As indicated in these two figures, the temperature drop across the honeycomb specimen assembled 


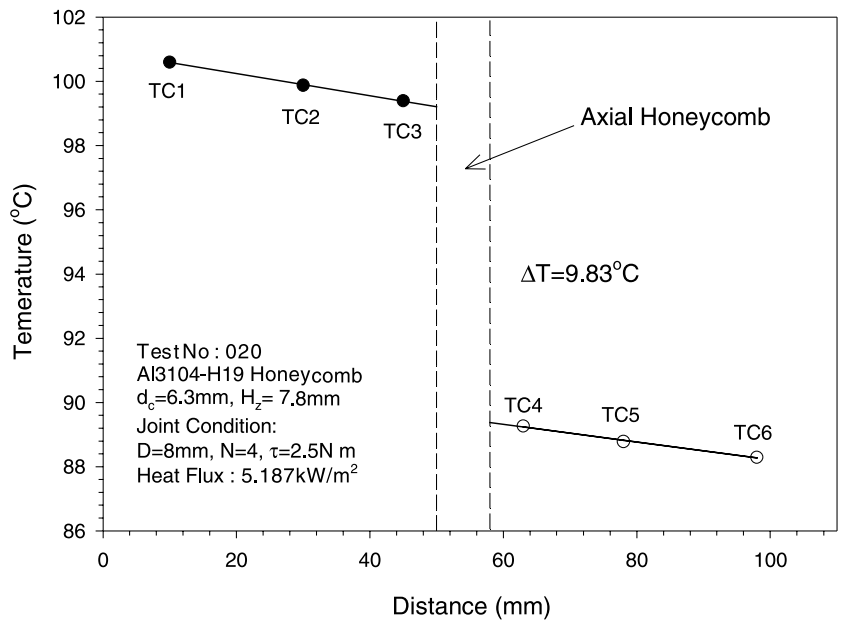

Fig. 4. Measured temperature drop across an axial honeycomb and temperature distribution of aluminum blocks.

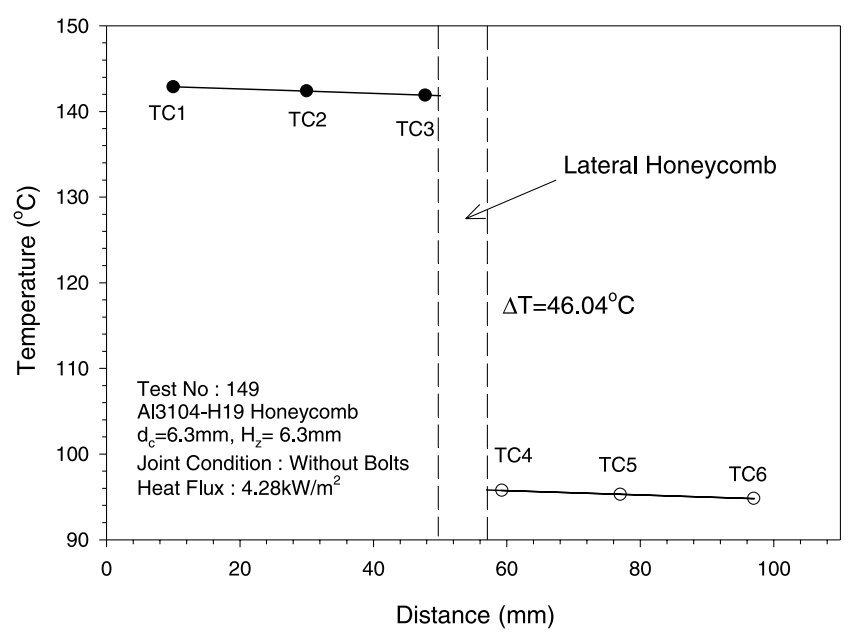

Fig. 5. Measured temperature drop across a lateral honeycomb and temperature distribution of aluminum blocks.

laterally is substantially larger than that aligned axially. This is partly because of the difference in the joint condition of honeycomb specimens. Four or eight bolts were used to sandwich the honeycomb specimen axially between two aluminum blocks, while in the lateral arrangement the honeycomb was simply inserted between two aluminum blocks. Based upon the previous study [17], the bolted joint could provide a very close interfacial contact, resulting in a relatively small temperature difference across the interface. In part, this could be due to the anisotropic nature in heat conduction of the honeycomb. This explanation will be further justified by the measured results of effective thermal conductivity discussed below.

Measured effective thermal conductivities $\left(k_{\mathrm{eff}}\right)$ of honeycomb specimens in both axial and lateral directions were summarized in Table 2. It was found that the effective thermal conductivity in the axial $(z)$ direction of
Table 2

Measured effective thermal conductivity of honeycomb specimens

\begin{tabular}{llll}
\hline $\begin{array}{l}\text { Specimen } \\
\text { no. }\end{array}$ & Orientation & $\begin{array}{l}\text { Measured } k_{\text {eff }} \\
(\mathrm{W} / \mathrm{m} \mathrm{K})\end{array}$ & $\begin{array}{l}\text { Calculated } \\
k_{\text {eff }}(\mathrm{W} / \mathrm{m} \mathrm{K})\end{array}$ \\
\hline 1 and 3 & Axial $(z)$ direction & $4.942 \pm 0.281$ & 5.03 \\
1 and 3 & Lateral $(y)$ direction & $1.910 \pm 0.126$ & 1.89 \\
2 and 4 & Axial $(z)$ direction & $2.733 \pm 0.106$ & 2.50 \\
\hline
\end{tabular}

honeycombs is larger than that in the lateral $(y)$ direction of honeycombs. This result implies that under the same heat flux the temperature gradient in the axial direction of a honeycomb should be smaller than that in the lateral direction. In addition, the honeycomb with a smaller cell size yields a higher effective thermal conductivity, due to a lower void ratio. It is useful to note that the calculated values listed in Table 2 were based upon the following equations [13], with an assumption of the hexagonal honeycomb.

$k_{\mathrm{eff}, z}=\left(\rho / \rho_{\mathrm{s}}\right) k_{\mathrm{s}} \quad$ and $\quad k_{\mathrm{eff}, y}=(3 / 8)\left(\rho / \rho_{\mathrm{s}}\right) k_{\mathrm{s}}$

A good agreement was obtained between the measured and calculated results. The minor discrepancy might be caused by the fact that not every honeycomb cell in the test specimens was a perfect hexagon.

\subsection{Axial total thermal conductance}

The total thermal conductance $\left(h_{\mathrm{t}, z}\right)$ in the axial direction of honeycomb specimens sandwiched by two aluminum blocks with four pieces of $8 \mathrm{~mm}$ bolts is presented in Fig. 6 as a function of applied torque. As shown in Fig. 6, under the condition of test specimens with the same height, the axial total conductance is noticeably higher for the honeycombs with a cell diameter $\left(d_{\mathrm{c}}\right)$ of $6.3 \mathrm{~mm}$ than that with $d_{\mathrm{c}}=12.7 \mathrm{~mm}$. This was mainly due to the greater effective thermal conductivity $\left(k_{\text {eff }}\right)$ of the honeycomb with a smaller cell di-

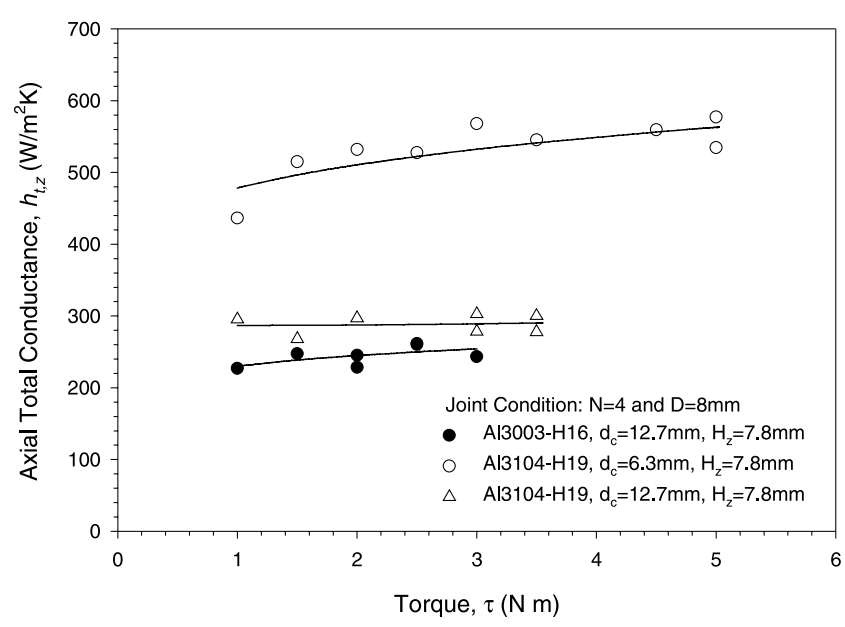

Fig. 6. Effects of applied torque, cell diameter, and material on the axial total thermal conductance of honeycombs. 
ameter. Moreover, for the honeycomb specimen with $d_{\mathrm{c}}=6.3 \mathrm{~mm}$, the axial total conductance increases with the torque applied on bolts. However, two types of honeycomb specimens with $d_{\mathrm{c}}=12.7 \mathrm{~mm}$ exhibit nearly constant axial total conductances with the torque varied from 1 to $3.5 \mathrm{Nm}$. These findings suggest that the influence of bolt torque on the interfacial heat transfer for honeycombs with $d_{\mathrm{c}}=12.7 \mathrm{~mm}$ is insignificant. Since the cross-sectional area provided by an axial honeycomb specimen of $d_{\mathrm{c}}=12.7 \mathrm{~mm}$ to make contact with upper or lower aluminum blocks was quite limited (about 58 $\mathrm{mm}^{2}$ ), an increase of torque yielded almost no enhancement of the interfacial contact. In addition, as shown in Fig. 6, the axial total conductance of honeycombs made of Al3104-H19 alloy is greater than that of A13003-H16 honeycombs, because the thermal conductivity of Al3104-H19 alloy is higher.

Effects of the joint condition on the axial total thermal conductance are presented in Figs. 7 and 8. For the honeycomb specimens with $d_{\mathrm{c}}=6.3 \mathrm{~mm}$, as shown in Fig. 7, an increase of either the bolt-shaft diameter (from 5 to $8 \mathrm{~mm}$ ) or the number of bolts (from 4 to 8 ) yields an obvious increase of the axial total conductance. Moreover, the total conductance increases with increasing torque for all three joint patterns. Similarly, for the honeycomb specimens with $d_{\mathrm{c}}=12.7 \mathrm{~mm}$, as shown in Fig. 8, an increase of the number of bolts results in an appreciable increase of total conductance. However, under the joint condition with the same number of bolts ( $N=4$ in Fig. 8), the total conductance of honeycombs with $d_{\mathrm{c}}=12.7 \mathrm{~mm}$ is not particularly affected by the increase in bolt-shaft diameter from 5 to $8 \mathrm{~mm}$. It was believed that when the bolt-shaft diameters (5 and $8 \mathrm{~mm}$ ) were smaller than the cell diameter (12.7 $\mathrm{mm}$ ) of honeycombs, the effect of bolt size on the enhancement of interfacial contact was less pronounced than that of the number of bolts. Fig. 8 also indicates

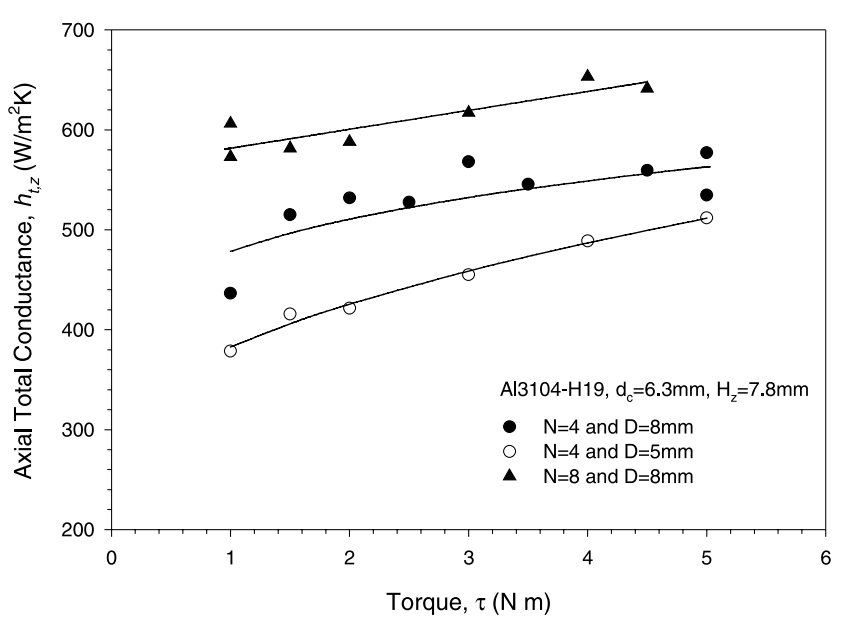

Fig. 7. Effects of different joint patterns on the axial total thermal conductance of honeycombs with $d_{\mathrm{c}}=6.3 \mathrm{~mm}$.

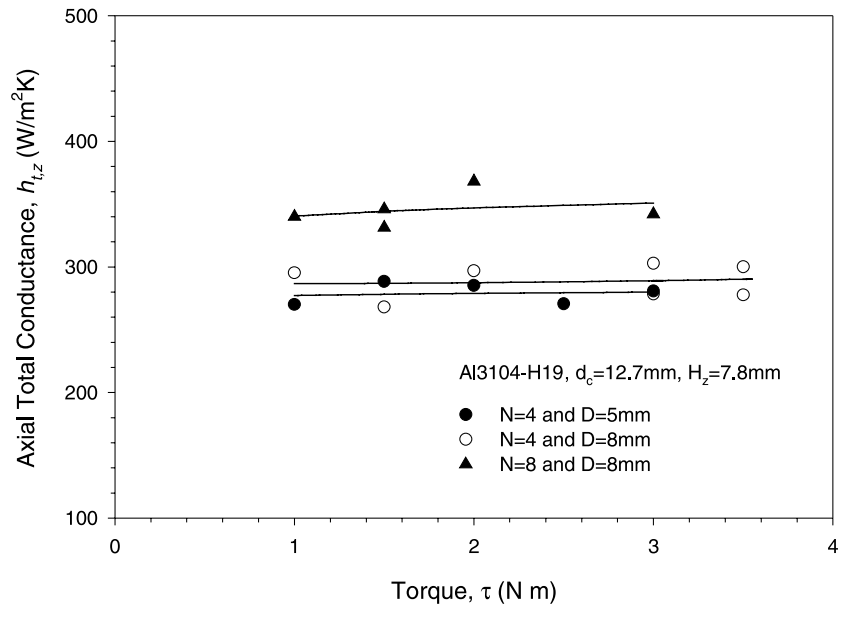

Fig. 8. Effects of different joint patterns on the axial total thermal conductance of honeycombs with $d_{\mathrm{c}}=12.7 \mathrm{~mm}$.

that for the honeycomb with $d_{\mathrm{c}}=12.7 \mathrm{~mm}$, regardless of the joint pattern, the total conductance is almost independent of the bolt torque between 1 and $3 \mathrm{Nm}$.

Fig. 9 shows the effect of specimen height on the total thermal conductance of axial honeycombs. It was evident in Fig. 9 that under the same joint condition the increase in the specimen height leads to a decrease of total conductance. This result can be explained by the increase in thermal resistance of honeycombs $\left(R_{\mathrm{HC}}\right)$ with increasing specimen height $\left(H_{z}\right)$, thus leading to a decrease of the total thermal conductance. For the honeycomb with $d_{\mathrm{c}}=6.3 \mathrm{~mm}$, the total conductance of honeycombs of $H_{z}=7.8 \mathrm{~mm}$ increases with increasing torque, but this dependency diminishes for the specimens with $H_{z}=14.8 \mathrm{~mm}$. This result suggests that a better contact through the increase in applied torque contribute little improvement of the heat transfer through an axial honeycomb with $H_{z}=14.8 \mathrm{~mm}$. This could also mean that for the honeycomb with

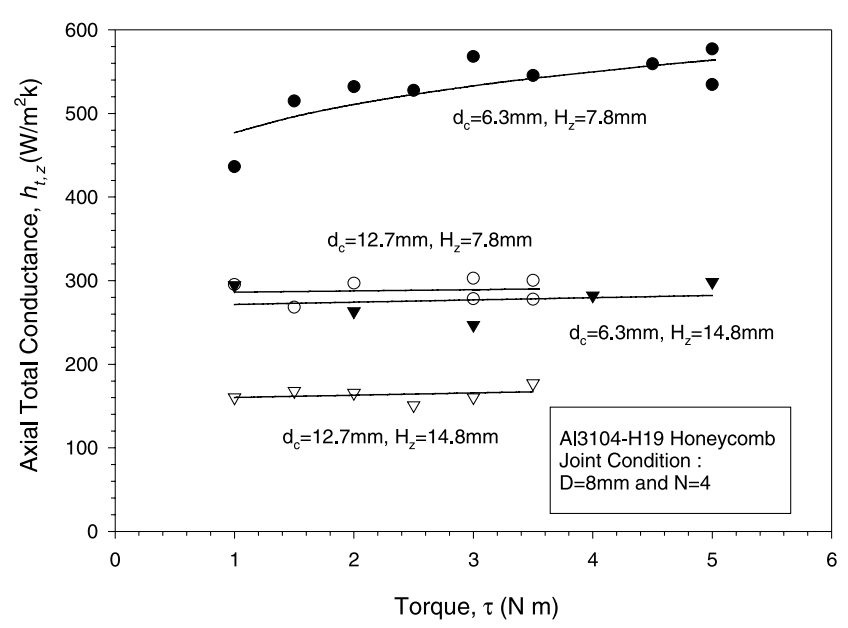

Fig. 9. Effects of specimen height on the axial total thermal conductance of honeycombs. 
$H_{z}=14.8 \mathrm{~mm}$ the total thermal resistance should be largely dominated by the resistance of honeycomb itself $\left(R_{\mathrm{HC}}\right)$.

\subsection{Lateral total thermal conductance}

The total thermal conductance $\left(h_{\mathrm{t}, y}\right)$ in the lateral direction of honeycombs with $d_{\mathrm{c}}=6.3 \mathrm{~mm}$ is shown in Fig. 10 as a function of the specimen height $\left(H_{y}\right)$. It should be noted that for lateral heat transfer tests the honeycomb specimens were sandwiched by two aluminum blocks without any bolts to tighten the whole assembly. In this study, the height of lateral honeycomb specimens was measured by the cell diameter $\left(d_{\mathrm{c}}\right)$ of honeycombs. Measured data, plotted in Fig. 10, represent four different heights $\left(H_{y}\right)$ with the dimensions equal to $1,1.5,2$, and 2.5 cell diameters, respectively. It was found that the lateral total conductance decreases with increasing specimen height, since the thermal resistance of honeycombs $\left(R_{\mathrm{HC}}\right)$ increases with the height. The effect of specimen orientation could be examined by a comparison of the results in Fig. 10 with those in Fig. 7. Obviously, the total conductance of honeycombs in the axial direction was considerably higher than that in the lateral direction. This could be attributed to the higher effective thermal conductivity of axial honeycombs, as well as by the lower thermal contact resistance of axial honeycombs due to a bolt joint.

\subsection{Thermal contact resistance}

Fig. 11 shows the total thermal resistance $\left(R_{\mathrm{t}}\right)$ and thermal contact resistance $\left(R_{\mathrm{c}}\right)$ of axial honeycomb specimens with $d_{\mathrm{c}}=6.3 \mathrm{~mm}$ and $H_{z}=7.8$ and $14.8 \mathrm{~mm}$. The total resistance is appreciably higher than the contact resistance. For the honeycomb specimens with $H_{z}=7.8 \mathrm{~mm}$, even though the contact resistance de-

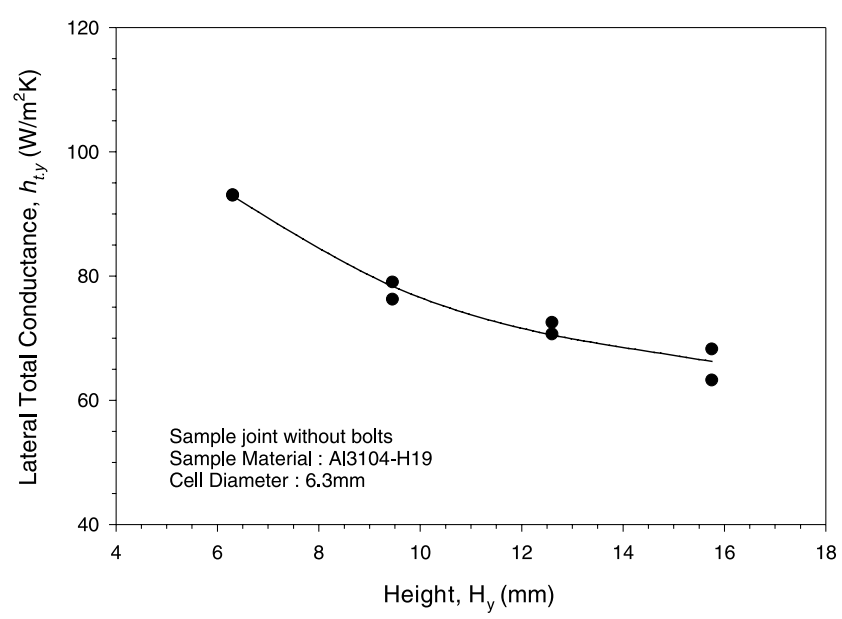

Fig. 10. Effects of specimen height on the lateral total thermal conductance of honeycombs.

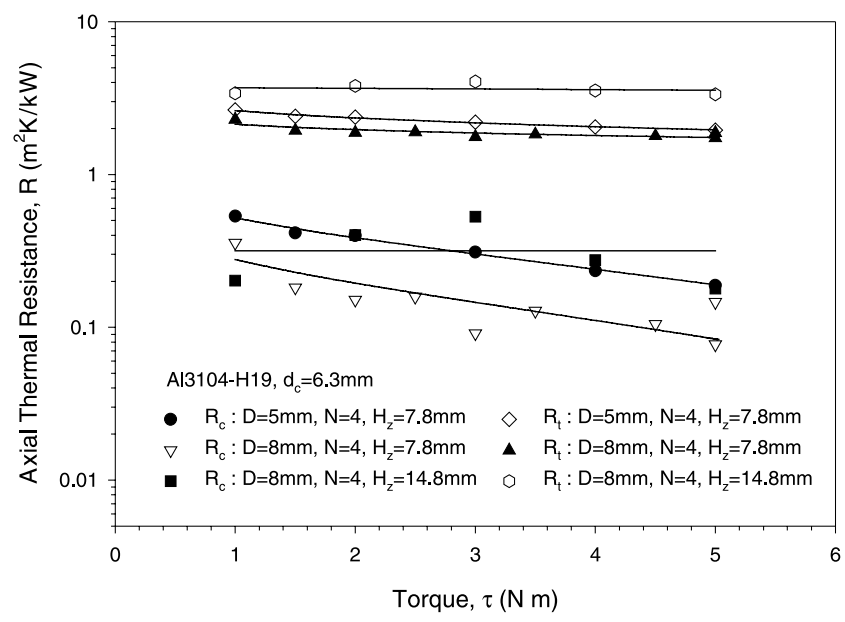

Fig. 11. Measured thermal total resistance and contact resistance of axial honeycombs with $d_{\mathrm{c}}=6.3 \mathrm{~mm}$.

creases substantially with the increasing torque, this decline only contributes a slight decrease of the total resistance. For the specimens with $H_{z}=14.8 \mathrm{~mm}$, it was believed that the influence of bolt torque on the interfacial contact becomes less notable, thus resulting in a slightly random variation of contact resistance with the torque.

Fig. 12 presents the axial data of thermal total resistance and contact resistance for the honeycomb specimens with $d_{\mathrm{c}}=12.7 \mathrm{~mm}$ and $H_{z}=7.8$ and 14.8 $\mathrm{mm}$. The total thermal resistance of honeycomb with $d_{\mathrm{c}}=12.7 \mathrm{~mm}$ is about an order of magnitude larger than the contact resistance. As shown in Fig. 12, the values of contact resistance for different specimen heights and joint patterns seem to be in the range between 0.2 and $0.4 \mathrm{~m}^{2} \mathrm{~K} / \mathrm{kW}$. This implies that for the honeycomb with $d_{\mathrm{c}}=12.7 \mathrm{~mm}$ the interfacial contact was not substantially affected by the joint pattern or specimen height. Therefore, the contribution of the axial

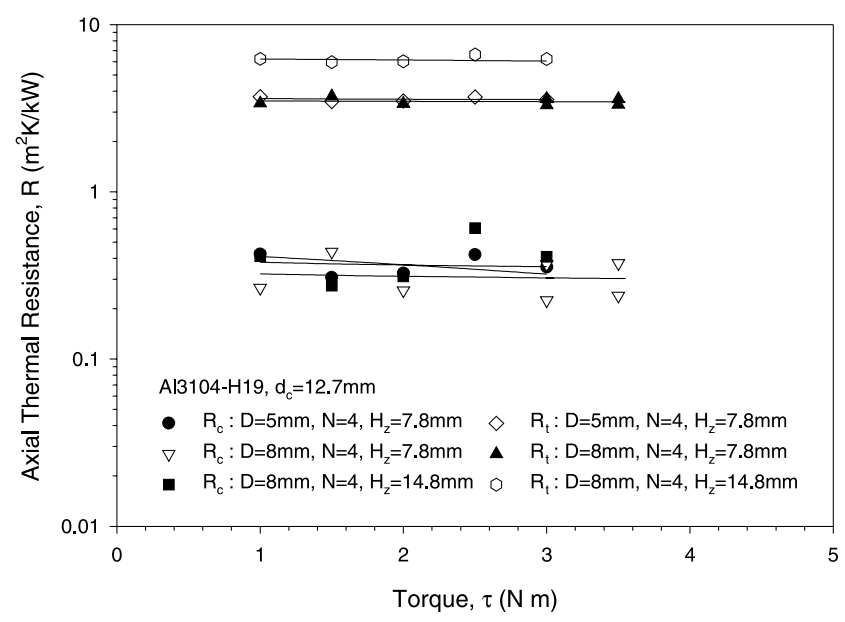

Fig. 12. Measured thermal total resistance and contact resistance of axial honeycombs with $d_{\mathrm{c}}=12.7 \mathrm{~mm}$. 
contact resistance to the total resistance becomes less significant for the honeycomb with a greater height.

The lateral data of thermal total resistance and contact resistance for the honeycomb specimens with $d_{\mathrm{c}}=6.3 \mathrm{~mm}$ was plotted in Fig. 13. It is evident that even though the total resistance decreases with the increasing height of honeycombs, the contact resistance remains nearly the same. The constant value of lateral contact resistance further confirms a consistent interfacial contact condition between the honeycomb specimen and aluminum blocks for all of the lateral tests conducted in this study. Unlike the axial results discussed in Figs. 11 and 12, the lateral contact resistance of honeycombs plays an important role in the total resistance, especially for the specimen with a small height. Even for a lateral specimen with a height equal to two and a half cell size $\left(2.5 d_{\mathrm{c}}\right)$, the sum of upper and lower contact resistances could account for $\approx 45 \%$ of the total resistance. For the sandwiched honeycomb with a lateral height of $H_{z}=d_{\mathrm{c}}$, the total thermal resistance was mainly dominated by the contact resistance, as shown in Fig. 13.

\subsection{Interfacial contact pressure of bolt-joined honey- combs}

The interfacial contact pressures of axial honeycombs under different bolt-joined conditions were measured by the pressure-measuring films. The deduced average contact pressures $\left(P_{\mathrm{c}}\right)$ as a function of joint conditions for the honeycombs with $d_{\mathrm{c}}=6.3$ and $12.7 \mathrm{~mm}$ are shown in Figs. 14 and 15, respectively. As shown in Figs. 14 and 15, the interfacial contact pressure increases with the applied torque on bolts. In addition, the double of the number of bolts $(N)$ leads to an observable increase in the contact pressure. The contact pressure also increase with the increase of bolt-shaft diameter $(D)$ from

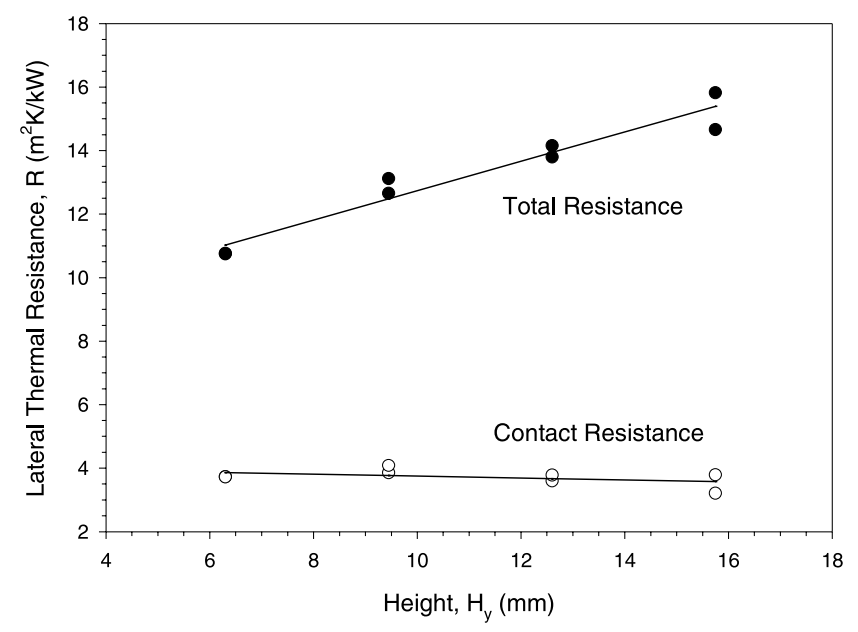

Fig. 13. Measured thermal total resistance and contact resistance of lateral honeycombs with $d_{\mathrm{c}}=6.3 \mathrm{~mm}$ as a function of specimen height.

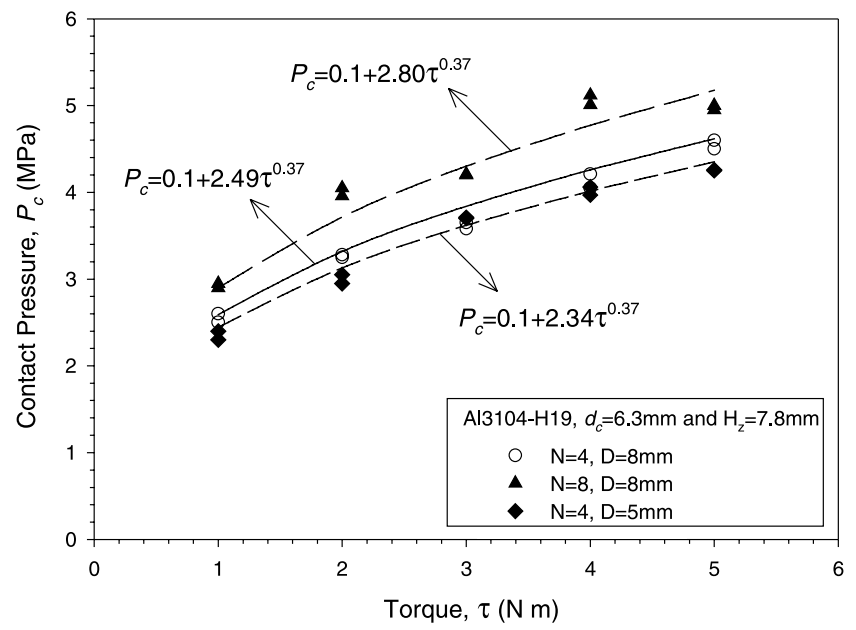

Fig. 14. Measured contact pressure in the interface of bolt-joined honeycombs with $d_{\mathrm{c}}=6.3 \mathrm{~mm}$.

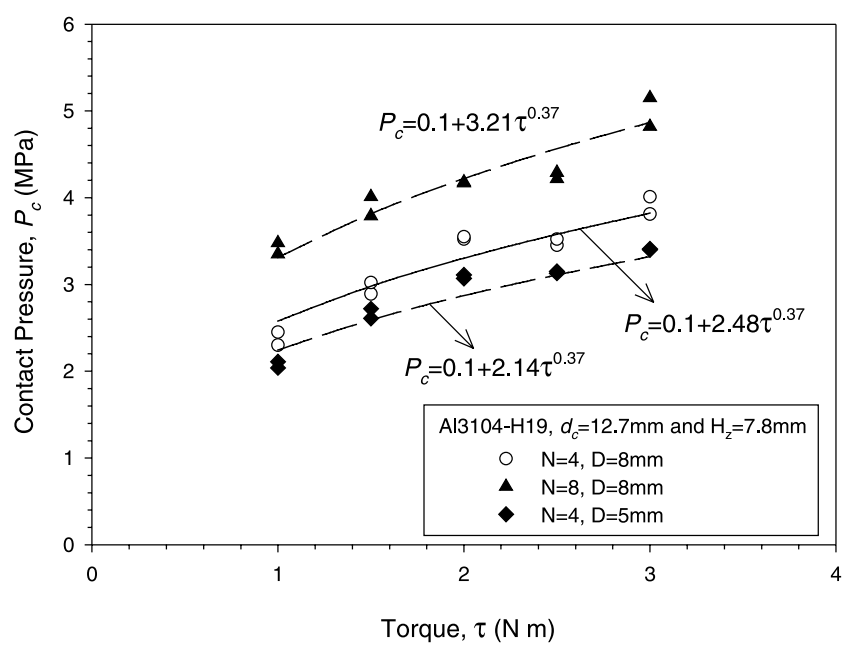

Fig. 15. Measured contact pressure in the interface of bolt-joined honeycombs with $d_{\mathrm{c}}=12.7 \mathrm{~mm}$.

5 to $8 \mathrm{~mm}$. However, in this study, the effect of bolt size on the contact pressure is not as significant as that of the number of bolts. Based upon the bolt-joined conditions, the empirical correlations between contact pressure and applied torque were expressed in the form of

$P_{\mathrm{c}}(\mathrm{MPa})=a+b \tau^{c}(\mathrm{Nm})$

where $a, b$, and $c$ are empirical constants. Correlations applied for different joint patterns are shown in Figs. 14 and 15.

\subsection{Measurement uncertainty}

Experimental uncertainties in the measured data, including total thermal conductance and contact resistance, result from errors in the measurement of effective thermal conductivity $\left(k_{\text {eff }}\right)$ of honeycombs, temperature drop $(\Delta T)$ and heat flux $(q)$ across the honeycomb 
specimen. The standard deviations of measured effective thermal conductivities are listed in Table 2, and the data uncertainty is about $\pm 5 \%$. The uncertainty in the temperature drop across honeycomb specimens is around $\pm 1 \%$, which is associated with the standard uncertainty of K-type thermocouples $\left(0.5^{\circ} \mathrm{C}\right)$, the error of data acquisition system $\left(0.5{ }^{\circ} \mathrm{C}\right)$, and the uncertainty of thermocouple position $(0.05 \mathrm{~mm})$ in test specimens. The uncertainty in $q$ was introduced by the uncertainty in the thermal conductivity of aluminum blocks (which was $\pm 3.2 \%$ ), and the deduced temperature gradients, which were known to an accuracy of $\pm 6.5 \%$ [17]. It is useful to note that the heat conduction through the bolts is negligible, due to the small area and low thermal conductivity. The natural convection in the enclosures of honeycomb cells is also negligible in this study. This is because the estimated Nusselt number and heat convection coefficient for the natural convection in honeycomb cells of $d_{\mathrm{c}}=12.7 \mathrm{~mm}$ are around 2.0 and $5.32 \mathrm{~W} /$ $\mathrm{m}^{2} \mathrm{~K}$, respectively [20]. As a result, the calculated heat flux by the natural convection is about $0.08 \mathrm{~kW} / \mathrm{m}^{2}$, which is much less than the heat flux (about $4-6.5 \mathrm{~kW} /$ $\mathrm{m}^{2}$ ) across the honeycomb. Based upon the uncertainty analysis proposed by Kline and McClintock [21], the average overall uncertainty of the data presented in this study was $8.5 \%$.

\section{Practical significance/usefulness}

This research was motivated by the lack of measured heat conduction properties of aluminum honeycombs. The results presented in this paper represent the first set of experimental data in thermal total conductance and contact resistance of aluminum honeycombs with the bolted joint. A series of measured data obtained in this study provides not only a better understanding of thermal conductance and contact resistance of honeycomb sandwich specimens, but also a database for practical applications. It is believed that these data will be also highly beneficial for the development and validation of theoretical models. Furthermore, the formulas used for the calculation of effective thermal conductivity of honeycombs were justified by the measured results in this study.

Due to the differences in material properties, geometric configurations, mounting patterns, junction characteristics, and specimen orientations, the scope of thermal contact resistance is very broad and complex. The results discussed in this paper point out the degree of contribution of the contact resistance to the total resistance for various honeycomb specimens and different joint conditions. This information provides thermal engineers a guideline to estimate the total thermal resistance, based upon the calculated effective thermal conductivity and the known honeycomb specification.

\section{Conclusions}

Based upon the experimental measurement and data analysis conducted in this study, several important results are summarized below.

1. The anisotropic nature of honeycombs in heat conduction was experimentally observed in this study. The effective thermal conductivity in the axial direction of honeycombs is larger than that in the lateral direction.

2. The influence of the bolt torque on the axial total conductance was observed only for the honeycomb with $d_{\mathrm{c}}=6.3 \mathrm{~mm}$ and $H_{z}=7.8 \mathrm{~mm}$. For the specimens with a larger cell diameter $\left(d_{\mathrm{c}}=12.7 \mathrm{~mm}\right)$ or axial height $\left(H_{z}=14.8 \mathrm{~mm}\right)$, the effect of applied torque became insignificant.

3. The axial total conductance of honeycombs increases with a decrease of either the cell size or specimen height. The effect of the number of bolts used in the assembly of honeycomb specimens on the axial total conductance is more appreciable than that of the bolt size.

4. Due to the anisotropic nature in heat conduction of honeycombs and the close contact provided by the bolted joints, the total conductance in the axial direction of honeycombs is greater than that of the lateral orientation under the condition with the same specimen height. Moreover, the lateral total conductance decreases with increasing specimen height.

5. The thermal contact resistance of axial honeycombs tested in this study, in general, is about an order of magnitude smaller than the total thermal resistance. Therefore, although the axial contact resistance of the honeycomb with $d_{\mathrm{c}}=6.3 \mathrm{~mm}$ and $H_{z}=7.8 \mathrm{~mm}$ decreases considerably with increasing bolt torque, this decrease of contact resistance only results in a slight decrease of the total conductance.

6. Due to the difference in the specimen joint conditions, the thermal contact resistance between an aluminum surface with a lateral honeycomb is larger than that with an axial honeycomb. However, the total resistance in the lateral direction is smaller than the axial total resistance because of the anisotropic nature of honeycombs. Therefore, the lateral contact resistance of honeycombs plays an important role in the total resistance, especially for the specimen with a small height.

7. The interfacial contact pressures of bolt-joined honeycombs were measured by the pressure-measuring films. The contact pressure increases with the applied torque on bolts. In addition, either the double of the number of bolts or the increase of bolt-shaft diameter leads to an increase in the contact pressure. The empirical correlations between contact pressure and applied torque were also obtained for different joint conditions. 


\section{Acknowledgements}

This research was sponsored by the National Space Program Office (NSPO) of Taiwan, ROC, under a contract number of NSC 90-NSPO(A)-PC-FD11-01. Authors are grateful to Dr. J.R. Tsai of NSPO for his valuable input and support of this project.

\section{References}

[1] W.E. Baker, T.C. Togami, J.C. Weydert, Static and dynamic properties of high-density metal honeycombs, Int. J. Impact Engng. 21 (3) (1998) 149-163.

[2] E. Wu, W.S. Jiang, Axial crush of metallic honeycombs, Int. J. Impact Engng. 21 (5-6) (1997) 439-456.

[3] W.C. Huang, C.F. Ng, Sound insulation improvement using honeycomb sandwich panels, Appl. Acoustics 53 (1-3) (1998) 163177.

[4] T.J. Lu, Heat transfer efficiency of metal honeycombs, Int. J. Heat Mass Transfer 42 (1999) 2031-2040.

[5] H.Z. Abou-Ziyan, R.F. Richards, Effect of gap thickness on a rectangular-cell compound-honeycomb solar collector, Solar Energy 60 (5) (1997) 271-280.

[6] N.D. Kaushika, M. Arulanantham, Radiative heat transfer across transparent honeycomb insulation materials, Int. Comm. Heat Mass Transfer 22 (5) (1995) 751-760.

[7] Y.S. Seo, S.K. Kang, M.H. Han, Y.S. Baek, Development of a catalytic burner with $\mathrm{Pd} / \mathrm{NiO}$ catalysts, Catalysis Today 47 (1999) 421-427.

[8] C.V. Madhusudana, L.S. Fletcher, Contact heat transfer-the last decade, AIAA J. 24 (3) (1986) 510-523.
[9] L.S. Fletcher, Recent developments in contact conductance heat transfer, ASME J. Heat Transfer 110 (1988) 1059-1070.

[10] M.A. Lambert, L.S. Fletcher, Review of the thermal contact conductance of junctions with metallic coatings and films, J. Thermophys. Heat Transfer 7 (4) (1993) 547-554.

[11] B. Snaith, S.D. Probert, P.W. O'Callaghan, Thermal resistances of pressed contacts, Appl. Energy 22 (1986) 31-84.

[12] M.R. Sridhar, M.M. Yovanovich, Review of elastic and plastic contact conductance models: comparison with experiment, J. Thermophys. Heat Transfer 8 (4) (1994) 633-640.

[13] T.J. Lu, C. Chen, Thermal transport and fire retardance properties of cellular aluminum alloys, Acta Mater. 47 (5) (1999) 1469 1485.

[14] S. Torquato, L.V. Gibiansky, M.J. Silva, L.J. Gibson, Effective mechanical and transport properties of cellular solids, Int. J. Mech. Sci. 40 (1) (1998) 71-82.

[15] E.K. Lakhal, E. Bilgen, P. Vasseur, Natural convection and conduction in inclined enclosures bounded by a wall with honeycomb structure, Int. J. Heat Mass Transfer 38 (8) (1995) 1397-1407.

[16] L.J. Gibson, M.F. Ashby, Cellular Solids: Structure and Properties, second ed., Cambridge University Press, Cambridge, 1997.

[17] C.L. Yeh, C.Y. Wen, Y.F. Chen, S.H. Yeh, C.H. Wu, An experimental investigation of thermal contact conductance across bolted joints, Exp. Thermal Fluid Sci. 25 (6) (2001) 349-357.

[18] J.K. Paik, A.K. Thayamballi, G.S. Kim, The strength characteristics of aluminum honeycomb sandwich panels, Thin-Walled Struct. 35 (1999) 205-231.

[19] H. Zhao, G. Gary, Crushing behavior of aluminum honeycombs under impact loading, Int. J. Impact Engng. 21 (10) (1998) 827836.

[20] F.P. Incropera, D.P. DeWitt, Fundamentals of Heat and Mass Transfer, fourth ed., John Wiley \& Sons, 1996.

[21] S.J. Kline, F.A. McClintock, Describing uncertainties in singlesample experiments, Mech. Engng. 75 (1) (1953) 3-8. 